\title{
TRANH CHÁP BIỂN ĐÔNG: THÁCH THỨC TRONG QUAN HỆ ASEAN - TRUNG QUỐC NHİN TỪ CÁCH TIẾP CẬN CỦA TRUNG QUỐC VỀ QUYỀN LỰC
}

\author{
Nguyễn Ngọc Anh* \\ Trung tâm Ngôn ngũu \& Quốc tế học, Trương Đại học Ngoại ngũu, ĐHQGHN \\ Phạm Văn Đồng, Cầu Giấy, Hà Nội, Việt Nam \\ Nhận bài ngày 14 tháng 09 năm 2016 \\ Chỉnh sửa ngày 29 tháng 12 năm 2016; Chấp nhận đăng ngày 04 tháng 01 năm 2017
}

Tóm tắt: Bài viết dựa trên lý thuyết quyền lực trong quan hệ quốc tế để xem xét cách tiếp cận của Trung Quốc trong tranh chấp Biển Đông với một số quốc gia ASEAN đặt trong tổng thể quan hệ ASEAN Trung Quốc và hệ quả của nó. Bài viết lập luận rằng, cách tiếp cận của Trung Quốc về quyền lực là nguồn lực sản sinh quyền lực, quyền lực dùng để ép buộc và giành thắng lợi trong xung đột. Vì vậy, khi nguồn lực của Trung Quốc lớn hơn thì khả năng xung đột trên Biển Đông giữa Trung Quốc với các nước ASEAN cũng sẽ gia tăng. Bài viết cho rằng một trong những giải pháp căn bản ngăn ngừa xung đột là tác động làm thay đổi cách tiếp cận của Trung Quốc về quyền lực.

Tù khóa: ASEAN, Trung Quốc, quyền lực, Biển Đông

\section{1. Đặt vấn đề}

Năm 1991, Trung Quốc trở thành Đối tác đối thoại của ASEAN và đến năm 1996 trở thành Đối tác đối thoại toàn diện của $\operatorname{ASEAN}^{(1)}$. Trung Quốc hiện là đối tác thương mại lớn nhất của ASEAN, ASEAN là đối tác lớn thứ 4 của Trung Quốc. Bên cạnh những thành tựu đạt được, quan hệ ASEAN - Trung Quốc cũng đã xuất hiện những thách thức mà nguyên nhân chính là do vấn đề tranh chấp Biển Đông. Quá khứ ám ảnh các quốc gia ASEAN về một Trung Quốc hùng mạnh sẽ bá chủ và thôn tính hoặc khống chế các quốc gia láng giềng yếu hơn. Khống chế Biển Đông được các nhà nghiên cứu đánh giá là bước đi thiết thực đầu tiên cho giấc mơ bá chủ này. Hành vi phủ định của Trung Quốc đối với phán quyết của Tòa Trọng tài quốc tế ngày 12/7/2016 đã tạo

* ĐT.: 84-912093346, Email: ngocanh2us@vnu.edu.vn

${ }^{1} \mathrm{http} / /$ www.aseanvietnam.vn/Default.aspx?page=intro duction\&introId $=48604$ ra những thách thức trong quan hệ ASEAN Trung Quốc. Tranh chấp Biển Đông không chỉ là vấn đề của một số nước trong $\mathrm{ASEAN}$ với Trung Quốc, mà là của cả khối ASEAN, thậm chí của cả thế giới vì $1 / 3$ lưu lượng thương mại quốc tế qua lại trên Biển Đông. Theo đánh giá của các học giả thì khống chế Biển Đông là một phần trong kế hoạch xưng bá ở Châu Á của Trung Quốc ${ }^{(2)}$. Nếu chiếm được Biển Đông, Trung Quốc sẽ có khả năng khống chế cả khối ASEAN, thậm chí cả những nước ngoài ASEAN. Do hành động của Trung Quốc trên Biển Đông luôn là nhân tố quyết định và nhân tố này lại được định hình bởi cách tiếp cận về quyền lực trong quan hệ quốc tế nên nghiên cứu này sẽ lý giải thách thức trong quan hệ ASEAN - Trung Quốc thông qua phân tích cách tiếp cận của Trung Quốc về quyền lực trong quan hệ quốc tế.

${ }^{2}$ http://www.fpri.org/article/2012/06/china-set-fornaval-hegemony/ 


\section{Tranh chấp Biển Đông: Thách thức trong quan hệ ASEAN - Trung Quốc}

Tranh chấp Biển Đông là một thách thức to lớn dẫn đến chia rẽ khối ASEAN, thậm chí tiềm ẩn nguy cơ xung đột giữa một số quốc gia trong ASEAN với Trung Quốc. Vì vấn đề tranh chấp Biển Đông mà Hội nghị Bộ trưởng ASEAN - Trung Quốc năm 2012 ở Campuchia lần đầu tiên không đưa ra được tuyên bố chung; Hội nghị đặc biệt Bộ trưởng ASEAN Trung Quốc tại Côn Minh Trung Quốc tháng 6/2016, do sức ép của Trung Quốc, bản tuyên bố chung ASEAN - Trung Quốc đã phải rút lại ${ }^{(3)}$; Hội nghị Bộ trưởng ASEAN - Trung Quốc tháng 7/2016 tại Lào sau rất nhiều căng thẳng và nỗ lực mới cho ra đời một bản tuyên bố chung nhưng đã xuất hiện sự bất đồng trong nội khối ASEAN ${ }^{(4)}$. Trung Quốc đã có những hành động quân sự làm leo thang căng thẳng với ASEAN như: năm 2011 cắt cáp tàu khảo sát của Việt Nam trong vùng đặc quyền kinh tế của Việt Nam; năm 2012 cưỡng chiếm bãi cạn Scarborough; năm 2014 hạ đặt trái phép giàn khoan HD 981 vào vùng đặc quyền kinh tế của Việt Nam; năm 2014 triển khai đội gồm 3 tàu tới bãi ngầm James chỉ cách Malaysia 80 km; năm 2015 tăng cường bồi đắp đảo và tăng tốc quân sự hóa ở Biển Đông; tháng 7/2016 tuyên bố phớt lờ phán quyết của Tòa Trọng tài bằng cả những động thái quân sự...

\section{Cưỡng ép và giành thắng lọii trong xung đột}

Quyền lực là "khả năng gây ảnh hưởng lên hành vi của người khác để đạt được kết quả mình mong muốn" (Joseph S. Nye, 2004). Có rất nhiều phương thức khác nhau để tác

\footnotetext{
$3 \mathrm{http} / /$ thediplomat.com/2016/06/china-not-asean-thereal-failure-at-south-china-sea-kunming-meeting/

4 http://www.reuters.com/article/us-southchinasearuling-asean-idUSKCN1050F6
}

động lên hành vi của người khác như cưỡng ép, đe dọa, sử dụng vũ lực, quyễn rũ, thuyết phục, khuyến khích, hợp tác, mua chuộc... Mỗi phương thức khác nhau sẽ mang lại kết quả khác nhau. Chẳng hạn như kết quả lý tưởng là chủ thể tác động dùng phương thức quyến rũ, khuyến khích và chủ thể bị tác động sẽ là tự nguyện làm theo. Mức thứ hai là chủ thể tác động dùng phương thức thuyết phục, hợp tác và chủ thể bị tác động sẽ cảm thấy hợp lý và chấp nhận được. Mức thứ ba, cũng là mức xấu nhất, là chủ thể tác động cưỡng ép, đe dọa, sử dụng vũ lực và chủ thể bị tác động sẽ buộc phải cam chịu khuất phục.

Trong lịch sử Trung Quốc đã từng xuất hiện cách tiếp cận khá hiện đại về quyền lực trong quan hệ quốc tế; đó là cách tiếp cận của Nho giáo. Cách tiếp cận này có những điểm tương đồng với cách tiếp cận “định hình tính quy chuẩn” (Hoàng Khắc Nam, 2011) - cách tiếp cận khoa học trong lý thuyết quan hệ quốc tế hiện đại. Khổng Tử từng nói: "Nếu như những người ở xa vẫn không chịu qui phục thì cần phải sửa lại lễ nhạc và nhân đức để khiến cho họ đến qui phục" (张燕英, 2007) hay "mềm mỏng với các nước xung quanh, bốn phía sẽ đến qui phục; vỗ về chư hầu, thiên hạ sẽ sợ phục" (吕友仁、吕咏 梅, 1998). Mạnh Tử phát triển tư tưởng của Khổng Tử cho rằng "người dựa vào vũ lực mượn danh nhân nghĩa để chinh phạt, có thể xưng bá chư hầu, nhưng đòi hỏi đất nước phải có tiềm lực rất mạnh; người dựa vào đạo đức, thực hiện nhân nghĩa có thể xưng vương thiên hạ, không nhất thiết đất nước phải có tiềm lực rất mạnh...dựa vào đạo đức khiến người ta đến qui phục, trong lòng người ta sẽ vui vẻ thuần phục" (杨伯峻, 1988). Cách tiếp cận này là sự dung hòa lợi ích của đôi bên theo hướng tự nguyện chấp nhận. 
Tuy nhiên, cách tiếp cận của hai ông ít được quan tâm, bản thân hai ông cũng không được trọng dụng. Cách tiếp cận nguồn lực (chủ yếu là quân sự) sinh ra quyền lực và mục tiêu của quyền lực là ép buộc, giành thắng lợi trong xung đột vẫn là chủ đạo trong lịch sử Trung Quốc. Biểu hiện chính của cách tiếp cận này là trong lịch sử Trung Quốc luôn định ra các mục tiêu ở nước ngoài cần thực hiện như lời nhận xét của học giả Bá Dương người Đài Loan là: "Dân tộc Trung Hoa là dân tộc dễ bành trướng nhất thiên hạ" (柏杨, 1986). Mỗi khi Trung Quốc có nguồn lực mạnh thì đe dọa hoặc phát động chiến tranh bắt các nước láng giềng phải khuất phục, Việt Nam là một ví dụ điển hình. Cách tiếp cận này có nguồn gốc từ tâm lý vượt trội trong so sánh nguồn lực, thường được gọi là tư tưởng Đại Hán, trong một không gian nằm trong tầm ảnh hưởng của Trung Quốc, hay còn gọi là "Thiên hạ", ở đó quan điểm của Trung Quốc là "bách tính Trung Quốc là thân, gốc rễ thiên hạ, Tứ Di chỉ là cành lá." (许嘉璐, 2004) và “Trung Quốc là nước lớn, các nước khác là nước nhỏ”(5).

Thế hệ lãnh đạo đầu tiên nước Cộng hòa Nhân dân Trung Hoa chịu ảnh hưởng rất lớn của cách tiếp cận này. Mao Trạch Đông nói: "Việc của Trung Quốc, xưa nay súng được dùng vào việc lớn” (中共中央文献研究室, 2008), "Chính quyền sinh ra từ họng súng... súng sinh ra tất cả...cả thế giới này chỉ có dùng súng mới thay đổi được" (中共中央文 献编辑委员会, 1991). Đặng Tiểu Bình đã vạch ra cho Trung Quốc bước đi trong cuộc chơi quyền lực đó là âm thầm tích lũy nguồn lực (resources), thường được gọi là "giấu mình chờ thời”. Biểu hiện rõ nét nhất của cách tiếp cận này là chiến lược "Bốn hiện đại

5 http://www.washingtonpost.com/wp-dyn/content/ article/2010/07/29/AR2010072906416.html hóa" (hiện đại hóa nông nghiệp, hiện đại hóa công nghiệp, hiện đại hóa quốc phòng, hiện đại hóa khoa học công nghệ) từ đầu thập niên 60 thế kỷ 20 , từ đó, tăng cường sức mạnh cho 3 thành tố quan trọng nhất cấu thành quyền lực là kinh tế, quốc phòng và khoa học kỹ thuật. Đặng Tiểu Bình từng phát biểu: "Khi thực hiện xong Bốn hiện đại hóa, kinh tế quốc dân phát triển rồi, chúng ta sẽ có thể đóng góp nhiều hơn cho nhân loại đặc biệt là thế giới thứ ba. Là nước Xã hội chủ nghĩa, Trung Quốc mãi mãi thuộc về thế giới thứ ba, vĩnh viễn không xưng bá... Nếu đến lúc đó Trung Quốc vênh mặt lên, xưng vương xưng bá, chỉ tay ra lệnh với thế giới, thì sẽ khiến cho chúng ta bị khai trừ khỏi thế giới thứ ba, chắc chắn sẽ không còn là nước Xã hội chủ nghĩa nữa" (中共中央文献编辑委员会，1993). Phát biểu này cho chúng ta biết cách tiếp cận của Đặng Tiểu Bình về quyền lực trong quan hệ quốc tế và từ cách tiếp cận đó có thể tiên liệu được những gì sau này có thể sẽ xảy ra khi các nghiên cứu chỉ ra rằng Trung Quốc không phải là nước Xã hội chủ nghĩa ${ }^{(6)}$. Minh chứng cho cách tiếp cận của Đặng Tiểu Bình là năm 1979 Trung Quốc phát động cuộc Chiến tranh Biên giới với Việt Nam kéo dài tới gần 10 năm, hay trận Hải chiến Trường Sa năm 1988 cướp đoạt một phần lãnh thổ của Việt Nam. Sau thời gian "giấu mình chờ thời" để củng cố và tăng cường nguồn lực, bước sang thế kỷ 21, đặc biệt đầu thập kỷ thứ 2 thế kỷ 21 , khi nguồn lực đã mạnh, cách tiếp cận này của Trung Quốc lại được thể hiện không chỉ bằng tuyên bố đe dọa sử dụng vũ lực mà bằng cả những hành động ngày càng tăng về số lượng và nguy hiểm về mức độ như ban hành các

\footnotetext{
6 http://nghiencuubiendong.vn/nghien-cuu-trungquoc/4878-trung-quoc-phien-ban-dac-biet-cua-chunghia-xa-hoi
} 
lệnh cấm, tăng cường quân sự hóa gồm: Bồi đắp đảo, xây đường băng, điều vũ khí hạng nặng ra Biển Đông ${ }^{(7)}$, tiến hành nhiều cuộc tập trận quy mô lớn, bắt bớ và ngược đãi các ngư dân... nhằm cưỡng ép và giành thắng lợi trong xung đột.

Biểu hiện cụ thể của cách tiếp cận ép buộc, giành thắng lợi trong xung đột trên Biển Đông của Trung Quốc gồm:

Đưa ra luật chơ ép các nuoớc khác tuân thủ

Trung Quốc tuyên bố có chủ quyền với 80\% diện tích Biển Đông, ban bố các lệnh cấm trên Biển Đông bắt các quốc gia khác phải tuân thủ.

\section{Trì hoãn và phủ nhận các giải pháp pháp lý}

Sau 10 năm (1992-2002) kiên trì đàm phán, ASEAN và Trung Quốc đã kí kết bản Tuyên bố về ứng xử của các bên ở Biển Đông (gọi tắt là D.O.C.). Tuy nhiên, một số học giả cho rằng D.O.C là "một văn kiện nửa chính trị nửa pháp lý và không có giá trị ràng buộc. Hiệu lực của văn bản này tùy thuộc vào thiện chí thi hành của các bên"(8). Khi ASEAN đề xuất đàm phán thỏa thuận mang tính ràng buộc pháp lý C.O.C thì Trung Quốc tìm cách trì hoãn. "Bộ quy tắc ứng xử mang tính ràng buộc C.O.C mà các bên đã cam kết hướng tới dường như đang bị lảng tránh, hay nói theo cách tích cực nhất là bị đóng băng, nhất là khi Trung Quốc cố ý trì hoãn đàm phán"(9) vì vậy "các cuộc tham vấn của ASEAN và Trung Quốc về một C.O.C mang tính ràng buộc có thể bị kéo dài, nếu không muốn nói là không thể kết thúc"

\footnotetext{
7 https://jamestown.org/program/beijing-ups-the-antein-south-china-sea-dispute-with-hq-9-deployment/

8 http://thediplomat.com/2016/06/china-not-asean-thereal-failure-at-south-china-sea-kunming-meeting/

9 http://www.nationmultimedia.com/opinion/We-needanother-name-for-the-South-China-Sea-30259386.html
}

(Carlyle A. Thayer, 2013). Đáng chú ý là phán quyết của Tòa Trọng tài quốc tế cũng bị Trung Quốc phủ nhận và coi đó là “tờ giấy lộn”(10).

Sủ dụng và đe dọa sủ dụng vũ lục

Trung Quốc đã dùng vũ lực đánh chiếm một số đảo, quần đảo ở Biển Đông như năm 1974 đánh chiếm quần đảo Hoàng Sa, năm 1988 đánh chiếm đảo Gạc Ma, năm 1995 đánh chiếm đảo Vành Khăn, 2012 cưỡng chiếm bãi cạn Scarborough, năm 2014 hạ đặt giàn khoan vào vùng đặc quyền kinh tế của Việt Nam trên Biển Đông...

Trung Quốc đe dọa sử dụng vũ lực không chỉ bằng những phát ngôn cứng rắn như lời tuyên bố của Bộ trưởng Bộ Quốc phòng Trung Quốc Thường Vạn Toàn(11) "không thỏa hiệp, không nhân nhượng, (và) không đánh đổi” và "quân đội Trung Quốc sẽ nhanh chóng tập hợp, sẵn sàng chiến đấu và giành chiến thắng”, mà còn là những cuộc tập trận quân sự với đội quân hùng hậu và vũ khí hạng nặng, tăng cường quân sự hóa trên Biển Đông, nguy hiểm hơn khi kêu gọi trang bị vũ khí cho ngư dân và sẵn sàng chiến tranh nhân dân trên biển ${ }^{(12)} \ldots$

\section{Giải pháp cho xung đột}

Với cách tiếp cận như trên, khả năng xảy ra xung đột sẽ tỷ lệ thuận với sự chênh lệch trong so sánh các nguồn lực chủ chốt sản sinh ra quyền lực giữa Trung Quốc và ASEAN. Chúng ta hãy xem xét sự tương quan giữa các nguồn lực chủ chốt:

\footnotetext{
${ }^{10}$ Nhân Dân Nhật báo, bản in tiếng Trung tháng 7 năm 2016: Ngày 10 trang 3 , ngày 11 trang 1 , ngày 12 trang 3 , ngày 13 trang 3 , ngày 14 trang 3 , ngày 17 trang 3 , ngày 21 trang 21

11 http://thediplomat.com/2014/07/china-and-strategicimbalance/2/

12 http://military.people.com.cn/n1/2016/0803/c101128606439.html
} 
Diện tích và dân số:

Biểu đồ so sánh diện tích và dân số giữa ASEAN với Trung Quốc

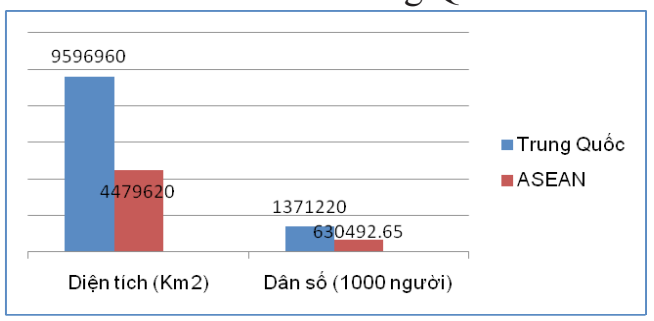

(Nguồn: CIA, truy cập tại: https://www.cia. gov/library/publications/the-world-factbook/ rankorder/2119rank.html; WorldBank, truy cập tại: http://data.worldbank.org/indicator/SP.POP.TOTL)

Diện tích của Trung Quốc lớn gấp 2,1 lần cả khối ASEAN và xếp thứ 3 thế giới. Dân số Trung Quốc lớn gấp 2,1 lần 10 quốc gia ASEAN, nhưng xếp số 1 thế giới. Trong đó, người Hán chiếm tới trên 91,5\% (trên 1,2 tỷ người) ${ }^{(13)}$ là một lợi thế lớn của Trung Quốc trong việc thống nhất sức mạnh tổng hợp. Ngoài ra, Trung Quốc còn có một lực lượng Hoa Kiều rất lớn lên tới 24 triệu người tại các quốc gia ASEAN và người Hoa nắm giữ huyết mạch kinh tế của các nền kinh tế lớn nhất ASEAN như Thái Lan, Malaysia, Singapore, Indonesia $^{(14)}$. Người Hoa cũng đã và đang cầm quyền tại một số quốc gia như Philippines (Tổng thống Corazon Aquino), Thái Lan (Thủ tướng: Thaksin, Yingluck), Singapore (Thủ tướng Lý Quang Diệu, Lý Hiển Long).....

Biểu đồ so sánh tỷ lệ \% người Hoa trên tổng dân số ở các quốc gia ASEAN

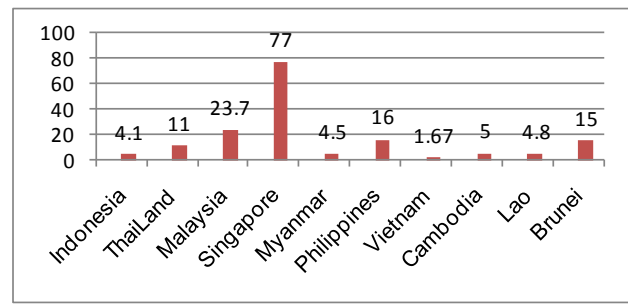

(Nguồn: Văn phòng Hoa Kiều Chính phủ Trung Quốc, truy cập tại: http://qwgzyj.gqb.gov.cn/ yjytt/155/1830.shtml)

\footnotetext{
${ }^{13} \mathrm{http} / / /$ www.stats.gov.cn/tjjj/pcsj/rkpc/6rp/indexch.htm ${ }^{14} \mathrm{http}$ //baotangnhanhoc.org/vi/tin-tuc-su-kien/su-kiennoi-bat/1084-ngi-hoa--ong-nam-a-th-lc-ang-gm.html
}

\section{Quân sụ}

Quân số và khí tài của quân đội Trung Quốc nhiều hơn cả 10 nước ASEAN cộng lại ${ }^{(15)}$. Chi phí quân sự thường được xem là yếu tố quan trọng hàng đầu giúp gia tăng sức mạnh quân sự. Chi phí quân sự của Trung Quốc tăng đều đặn và luôn gấp hơn 5 lần so với cả khối ASEAN. Khoảng cách chi phí quân sự giữa Trung Quốc và ASEAN ngày càng gia tăng, nếu năm 2010 là 110.8 tỷ USD, thì năm 2015 đã là 172.8 tỷ USD.

Biểu đồ so sánh chi phí quân sự giữa Trung Quốc và ASEAN giai đoạn 2010-2015

(Đơn vị: Tỷ USD)

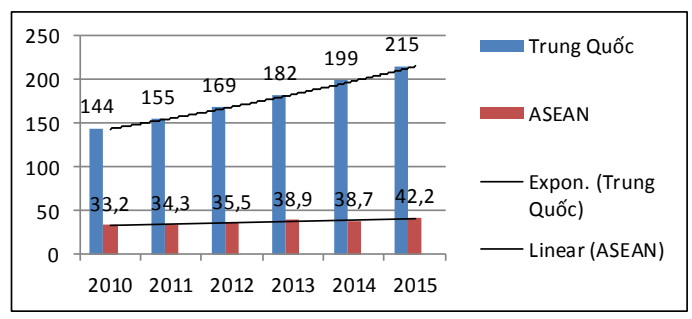

(Nguồn: Viện nghiên cứu hòa bình quốc tế Stockholm, truy cập tại: https://www.sipri.org/ databases/milex)

\section{Kinh tế}

GDP của Trung Quốc xếp thứ 2 thế giới, nhưng dự trữ ngoại hối lại xếp số 1 thế giới, cả hai đều lớn gấp gần 5 lần so với cả khối ASEAN.

Biểu đồ so sánh GDP và dữ trữ ngoại hối giữa ASEAN và Trung Quốctính đến năm 2015 (Đơn vị: Tỷ USD)

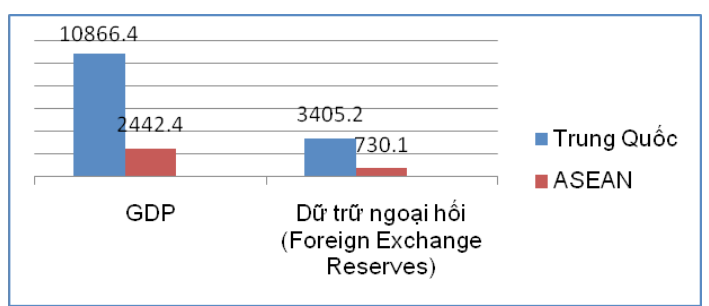

(Nguồn: Ngân hàng Thế giới, truy cập tại: http:// data.worldbank.org/indicator/FI.RES.TOTL.CD)

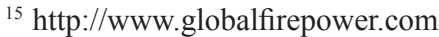




\section{Công nghệ}

Số lượng sáng chế là một trong những yếu tố quan trọng phản ánh trình độ công nghệ của quốc gia. Tổng số lượng sáng chế áp dụng tại Trung Quốc gấp gần 22 lần $\mathrm{ASEAN}$, gấp 1,6 lần Hoa Kỳ (578802). Nhưng quan trọng nhất là số lượng sáng chế của người bản địa Trung Quốc (801135/928177, chiếm tới 86\%) gấp 153 lần số lượng sáng chế của người bản địa $\operatorname{ASEAN~(5213/42212,~chỉ~chiếm~12\% ),~}$ gấp 2,8 lần Hoa Kỳ (285096). Đầu tư cho KHCN của Trung Quốc gấp 17 lần $\operatorname{ASEAN}^{(16)}$.

Biểu đồ so sánh sáng chế và kinh phí khoa học-công nghệ giữa ASEAN và Trung Quốc 2015

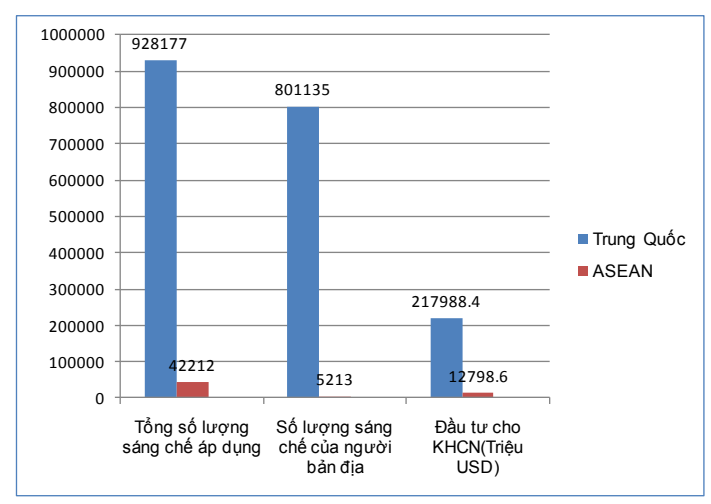

Nguồn $^{(17)}$ : World Intellectual Property Indicators 2015 và The Global Innovation Index 2015

(Ghi chú: Mục đầu tư cho KHCN không có thông tin 4 quốc gia: Brunei, Capuchia, Myanmar và Lào)

Qua những so sánh trên có thể thấy, nguồn lực của Trung Quốc vượt trội so với cả khối ASEAN. Với cách tiếp cận nguồn lực sinh ra quyền lực, quyền lực để ép buộc khuất phục và giành thắng lợi trong xung đột thì Trung Quốc sẽ tăng cường răn đe, áp

\footnotetext{
${ }^{16}$ Không có số liệu đầu tư cho KHCN của 4 quốc gia: Brunei, Capuchia, Myanmar và Lào

17 http://www.wipo.int/edocs/pubdocs/en/wipo_pub 941 2015.pdf

https://www.globalinnovationindex.org/userfiles/file/ reportpdf/GII-2015-v5.pdf
}

đặt, nguy cơ xảy ra những xung đột vì thế sẽ rất cao.

Tuy nhiên, quyền lực và thực thi quyền lực phụ thuộc vào 3 yếu tố là nguồn lực, năng lực sử dụng nguồn lực của chủ thể và những nhân tố bên ngoài (nằm ngoài các chủ thể) làm tăng giảm quyền lực.

Tiết Lực, Viện trưởng Viện Nghiên cứu Chiến lược quốc tế thuộc Viện Hàn lâm khoa học xã hội Trung Quốc từng nói: "Bản thân Trung Quốc cũng không biết mình muốn gì trên Biển Đông, có những quyền lợi cụ thể nào?"(18). Câu nói này mâu thuẫn với những tuyên bố về yêu sách chủ quyền của Trung Quốc trên Biển Đông, có lẽ điều mà Trung Quốc không biết ở đây là đâu là lợi ích tối đa sẽ đạt được và thời điểm nào, bằng cách nào để đạt được lợi ích tối đa đó.

Hội nhập và toàn cầu hóa đã làm gia tăng đáng kể sức mạnh của những nhân tố bên ngoài trong quan hệ quốc tế. Sai lầm thường thấy là khi chủ thể quá coi trọng sự chênh lệch về nguồn lực hoặc đánh giá quá cao năng lực sử dụng nguồn lực của mình, trong khi đó lại không đánh giá hết được những nhân tố bên ngoài nhưng lại có tác động làm tăng hoặc giảm khả năng thực thi quyền lực của các chủ thể. Những sai lầm nghiêm trọng đã xảy ra như Hoa Kỳ tham chiến tại Việt Nam (1954-1975) và Trung Quốc phát động cuộc chiến tranh biên giới với Việt Nam (1979). Nguyên nhân sai lầm chủ yếu là do nguồn lực là yếu tố dễ nhận biết, dễ đánh giá nhất và năng lực sử dụng nguồn lực thường được đánh giá dựa trên lý thuyết và kinh nghiệm. Trong khi đó, những nhân tố bên ngoài (nhiều khi là ẩn số) nhưng lại có thể làm tăng hoặc giảm đáng kể khả năng thực thi quyền lực của chủ thể thì lại rất khó đánh giá hết. Một ví dụ khác là nguồn lực và năng lực

$18 \mathrm{http} / /$ thediplomat.com/2016/07/interview-xue-li-onthe-south-china-sea/ 
sử dụng nguồn lực của Hoa Kỳ được đánh giá là số 1 thế giới, tuy nhiên sau hơn 50 năm, Hoa Kỳ vẫn không thể hoàn thành được mục tiêu và lợi ích tại Cuba. Gần đây, để thực thi quyền lực, Hoa Kỳ đã phải thay đổi cách tiếp cận về mục tiêu của quyền lực trong quan hệ với Cuba. Một ví dụ nữa là dù trải qua hàng chục năm xung đột, Israel không thể xóa bỏ được nhà nước Palestine. Một ví dụ gần nhất là cuộc chiến tại Syria do Hoa Kỳ dẫn dắt, cục diện hiện tại vẫn nằm ngoài khả năng của cả hai chủ thể là Hoa Kỳ và Syria.

Trung Quốc từng kêu gọi các bên gác tranh chấp cùng khai thác. Ngày 1/7/2016, trong diễn văn kỉ niệm 95 năm thành lập Đảng Cộng sản Trung Quốc, Tổng Bí thư Đảng Cộng sản Trung Quốc Tập Cận Bình đã kêu gọi thực hiện chính sách đối ngoại "lấy hợp tác thay đối đầu, lấy cùng thắng thay độc chiếm"(19), tuy nhiên, sau đó tuyên bố: "Dù là quốc gia nào cũng đừng mơ Trung Quốc sẽ chấp nhận đem các 'lợi ích cốt lôi' của mình đi đổi chác, đừng mơ Trung Quốc sẽ chấp nhận ăn 'trái đắng' tổn hại đến chủ quyền, an ninh và lợi ích phát triển quốc gia"(20). Tuyên bố này nếu ám chỉ tranh chấp Biển Đông thì mọi nỗ lực để giải quyết tranh chấp đều sẽ trở nên vô nghĩa. Biển Đông hiện không chỉ là vấn đề chủ quyền của các bên có tuyên bố chủ quyền, mà còn là lợi ích của rất nhiều quốc gia trong đó có các cường quốc hàng đầu thế giới như Hoa Kỳ, Nhật Bản, Ân Độ, là vấn đề an ninh của cả khu vực Châu Á Thái Bình Dương. Bên cạnh đó còn có các thể chế quốc tế như Liên hợp quốc, Tòa án quốc tế, Tòa Trọng tài quốc tế...được bảo trợ bởi các quy tắc, luật

${ }^{19}$ Nhân Dân Nhật báo (phiên bản hải ngoại), số ra ngày 2/7/2016, Trg3

${ }^{20}$ Nhân Dân Nhật báo (phiên bản hải ngoại), số ra ngày 2/7/2016, Trg3 pháp và công ước. Một sức mạnh đáng kể nữa là dư luận quốc tế. Tất cả tạo nên sức mạnh tổng hợp làm suy yếu quyền lực, đặc biệt là quyền lực mềm của Trung Quốc trong quan hệ quốc tế nếu Trung Quốc không thay đổi cách tiếp cận.

Trung Quốc hiện là đối tác thương mại lớn nhất của ASEAN, ASEAN là đối tác thương mại lớn thứ 4 của Trung Quốc, lợi ích kinh tế và tiềm năng hợp tác giữa hai bên rất lớn. Không một quốc gia nào trong ASEAN muốn và đủ khả năng gây nên mối đe dọa đối với Trung Quốc và không một quốc gia nào trên thế giới có thể bất chấp luật pháp và dư luận quốc tế để làm theo ý mình. Đối với ASEAN, dù Trung Quốc đưa ra những khẩu hiệu, phương châm tốt đến mấy, đi kèm với đó là những chương trình, dự án hợp tác và những khoản tiền khổng lồ... thì cũng không thể so sánh được với chủ quyền lãnh thổ và tự do hàng hải. Đối với các quốc gia trong ASEAN, việc nâng cao nguồn lực và năng lực sử dụng nguồn lực là rất quan trọng. Một điểm đáng chú ý là hiện đại hóa quân đội để tự vệ là cần thiết, tuy nhiên, với tiềm lực kinh tế như hiện nay sẽ không dễ để có thể hiện đại hóa đến mức khiến cho Trung Quốc phải chùn bước, thậm chí nếu không thận trọng dễ dẫn đến căng thẳng hoặc xung đột. Bất cứ ý tưởng hay hình thức đối đầu nào đều dẫn đến bế tắc và xung đột. Song song với nâng cao nguồn lực và năng lực sử dụng nguồn lực, các quốc gia trong ASEAN cần đoàn kết, không ngừng tăng cường và tận dụng sức mạnh của các nhân tố bên ngoài để tác động làm thay đổi cách tiếp cận của Trung Quốc, từ đó hình thành nên các chuẩn mực buộc Trung Quốc phải tuân thủ.

Một trong những giải pháp căn bản là Trung Quốc thay đổi cách tiếp cận theo hướng dung hòa lợi ích của các bên, từ đó cho ra đời bản C.O.C phù hợp với các chuẩn mực quốc tế và mang tính ràng buộc về mặt pháp lý để giải quyết tranh chấp 
Biển Đông. Khi đó, lòng tin sẽ được củng cố, hợp tác sẽ được tăng cường, những nguy cơ xung đột trên Biển Đông sẽ được khống chế. Có như vậy mới góp phần giải quyết được thách thức giữa ASEAN và Trung Quốc một cách bền vững.

\section{Tài liệu tham khảo}

\section{Tiếng Việt}

Hoàng Khắc Nam (2011). Quyền lực trong quan hệ quốc tế, lịch sủ và vấn đề. Hà Nội: Nxb Văn hóa thông tin.

Đặng Đình Quý (2011). Biển Đông - Hướng tới môt khu vưc hòa bình, an ninh và hợp tác. Hà Nội: Nxb Thế giới.

\section{Tiếng Trung}

中共中央文献研究室 (2008). 《毛泽东年

谱》. 北京: 中央文献出版社

中共中央文献编辑委员会 (1991)。 《毛泽东选

集》. 北京：人民出版社

中共中央文献编辑委员会 (1993). 《邓小平文

选》. 北京: 人民出版社

张燕英译注 (1998). 《论语》. 北京: 中华书局
吕友仁、吕咏梅译注 (1998). 《礼记-孝经全 译》. 贵阳: 贵州出版社

杨伯峻（1988）. 《孟子译注》. 北京: 中华书局 柏杨 (1986). 《丑陃的中国人》. 长沙: 湖南 文艺出版社

许嘉璐 (2004). 《二十四史全译》. 北京: 汉 语大词典出版社

中国共产党. 《人民日报》. 北京: 人民出版社

\section{Tiếng Anh}

Joseph S. Nye (2004). Soft Power: The Means to Success in World Politics. New York: Public Affairs.

Carlyle A. Thayer (2013). ASEAN, China and the Code of Conduct in the South China Sea, SAIS Review of International Affairs, Vol.33, No.2.

Tim Dunne, Milja Kurki, Steve Smith (2013). International Relations Theories Discipline and Diversity. Oxford: Oxford University Press.

Karen A Mingst, Ivan M Arreguin - Toft (2014). Essentials of International Relations. New York: W.W. Norton\&Company.

Robert Dahl (1957). Concept of Power. Behavioral Science, 2:3.

\title{
SOUTH CHINA SEA DISPUTE: THE CHALLENGE TO THE ASEAN - CHINA RELATIONSHIP FROM CHINA'S PERSPECTIVE OF POWER
}

\author{
Nguyen Ngoc Anh
}

\begin{abstract}
Center of Linguistics and International Studies, VNU University of Languages and International Studies, Pham Van Dong, Cau Giay, Hanoi, Vietnam
\end{abstract}

\begin{abstract}
With reference to power theories in international relation, the research analyzed China's views on disputes in South China sea with some ASEAN countries placed in the overall of China - ASEAN relationship and its consequences. The research argues that China's approach of power is resourses bring power and power is to force others and win conflicts. Therefore, the stronger China's resources, the higher the possibility of conflict in South China sea between China and some ASEAN countries. The research posits that one of the basic solutions to prevent conflicts is making China change its approach of power.
\end{abstract}

Keywords: ASEAN, China, power, South China sea 